\title{
Análise do Programa "CAChe for Windows"
}

J O Ã O P A U L O L E A L *

\begin{abstract}
O Programa CAChe ${ }^{\circledR}$ for Windows (Computer Aided Chemistry) é comercializado pela Oxford Molecular Ltd. e funciona quer no sistema Microsoft Windows 95 quer em Microsoft Windows NT 4.0®. Permite desenhar e modelar moléculas bem como efectuar cálculos sobre essas moléculas determinando propriedades moleculares ou valores de energia. O programa pode ser adquirido em vários níveis de potencialidades/ /funcionalidades/preços desde $o$ mais básico Personal CAChe até ao mais elaborado $C A C h e$ WorkSystem passando pelo já muito potente Quantum CAChe. Existe ainda o CAChe Satellite que funciona como uma estação de trabalho do CAChe WorkSystem tornando-se bastante atractivo para soluções multiposto. $\mathrm{O}$ modelo analisado foi o Quantum CAChe versão 3.0 .
\end{abstract}

Um dos pontos agradáveis do programa é o facto de não ser necessário construir tabelas de dados ou matrizes de conectividade. A introdução dos dados é feita construindo a molécula de modo semelhante ao que se faz num programa de dese- nho de moléculas. No que diz respeito à construção da molécula existem as funcionalidades esperadas. Para cada átomo (qualquer um da Tabela Periódica até ao 103) pode escolherse a sua hibridação e carga, a cor, o tipo de textura dos átomos (sombreado, ponteado ou tipo esfera armilar) e ainda a escala entre o raio de Van der Waals e o raio representado. No que se refere às ligações pode escolher-se entre simples, duplas, triplas, fracas ou coordenadas. Pode ainda optar-se por representar as ligações múltiplas por uma linha/cilindro mais grossa/o ou por múltiplas/os linhas/cilindros. Realça-se a possibilidade de ligações fracas (importante p. ex. quando existem pontes de hidrogénio) e de ligações coordenadas que podem ligar um átomo ao meio de uma outra ligação (em organometálicos com p. ex. ligações $\eta^{2}$ fica tudo simplificado). Igualmente útil é o botão do Beautify (Embelezar) que permite automaticamente corrigir a valência, as hibridações, os anéis e a geometria de uma molécula (cada uma de per si ou todas as opções em simultâneo). Basta assim desenhar o esqueleto da molécula e actuar $\boldsymbol{B} \boldsymbol{e}$ autify para que sejam colocados os hidrogénios necessários e sejam cor- rigidos os comprimentos das ligações e os ângulos entre elas.

Uma vez desenhada a molécula podemos alterar tudo o que pretendermos e como é costume, ver a molécula representada como linhas, bolas e cilindros ou como esferas com os respectivos raios de Van der Waals. Podemos também rodá-la nos três eixos, aumentá-la ou diminui-la e deslocá-la à nossa vontade. E já tendo a molécula, vamos gravá-la e partir para os cálculos.

A quantidade de propriedades que se podem calcular é grande (Tabela 1) e para o seu cálculo existem uma série de ferramentas disponíveis (Mecânica Molecular, MOPAC, Hückel Estendido, Zindo e Dinâmica Molecular). É certo que nem todas as ferramentas devem ser utilizadas para qualquer dos cálculos destas propriedades e que em alguns casos os elementos existentes na molécula condicionam a escolha da ferramenta. Enquanto que a mecânica molecular ou o método de Hückel podem ser utilizados para qualquer dos elementos, já para o MOPAC o número de elementos que se encontra parametrizado (e que portanto pode ser usado) é menor e depende da parametrização: AMI ou PM3.

\section{Tabela 1 - Propriedades passíveis de serem calculadas usando o CAChe}

Propriedades da Molécula

Entalpia de formação

Transições UV-Visível

Transições IV

Energia Actual

Densidade Electrónica

HOMO e LUMO

HOMO-5 até $\mathrm{LUMO}+4$

Todas Orbitais Moleculares

Isopotencial Electrostático

Susceptibilidade Electrofílica

Susceptibilidade Nucleofílica

Susceptibilidade Radical

Superdeslocalização

Electrofílica

Superdeslocalização

Nucleofílica

Superdeslocalização Radical

Propriedades Atómicas

Carga Parcial
Propriedades das Ligações

Ordem de Ligação

Tensão (strain) da ligação

Propriedades

Conformacionais

da Molécula

\author{
Mapa Rígido \\ Mapa Optimizado \\ Sequência de Conformações \\ Trajectória Dinâmica
}

Propriedades

Reaccionais e de

Estado de Transição

Mapa da Reacção

Procura de Sela

Refinamento Est.Transição

Verificação Est. Transição

Procura de Caminhos

Reaccionais 
Tabela 2 - Entalpias de formação $(\mathbf{k J} / \mathrm{mol})$ para várias moléculas

\begin{tabular}{|c|c|c|c|c|c|}
\hline & MOPAC(PM3) & MOPAC(AM1) & Experimental & $\begin{array}{c}\text { Estado } \\
\text { Físico }\end{array}$ & Ref. \\
\hline \multirow[t]{2}{*}{$\mathrm{H} 2 \mathrm{O}$} & -223.53 & -247.86 & -241.82 & $\mathrm{~g}$ & 1 \\
\hline & -258.77 & -286.18 & -285.83 & 1 & 1 \\
\hline $\mathrm{C} 6 \mathrm{H} 14$ & -166.90 & -187.23 & -167.1 & $\mathrm{~g}$ & 2 \\
\hline LiOMe & -199.04 & n.a. & -217 & $\mathrm{~g}$ & 3 \\
\hline
\end{tabular}

n.a. Não existe parametrização para o lítio em AM1.

Sendo a quantidade de opções muito elevada vai-se apenas analisar neste breve comentário algumas delas a título de exemplo.

A primeira propriedade analisada foi a entalpia de formação. Utilizaram-se três moléculas diferentes umas das outras: água, hexano e metóxido de lítio. Os resultados obtidos estão apresentados na Tabela $2 \mathrm{e}$ pode ver-se que, no que se refere às moléculas na fase gasosa, para a água a parametrização AMl dá os melhores resultados enquanto que para o hexano os melhores resultados são obtidos com os parâmetros PM3. Para o etóxido de lítio só um dos conjuntos de parâmetros pode ser usado. A concordância, mesmo nos piores casos, é melhor que $20 \mathrm{~kJ} / \mathrm{mol}$. Quando não existem valores experimentais é de ter em conta uma estimativa destas. Para a água no estado líquido utilizou-se uma opção muito interessante que o programa possui. Trata-se de calcular a entalpia de formação da molécula em água. Assim calculou-se a ental- pia da molécula de água, dissolvida em água. De novo a parametrização AMl dá melhores resultados mas mesmo o pior valor só se desvia cerca de $25 \mathrm{~kJ} / \mathrm{mol}$. Nada mau.

Aproveitando o facto de ter o hexano e a água (Fig. 1) em memória e nas respectivas estruturas optimizadas, calcularam-se as transições esperadas no infravermelho. Os resultados obtidos (Fig. 2 e 4) são comparados com os espectros experimentais para as mesmas moléculas (Fig. 3 e 5) [4].

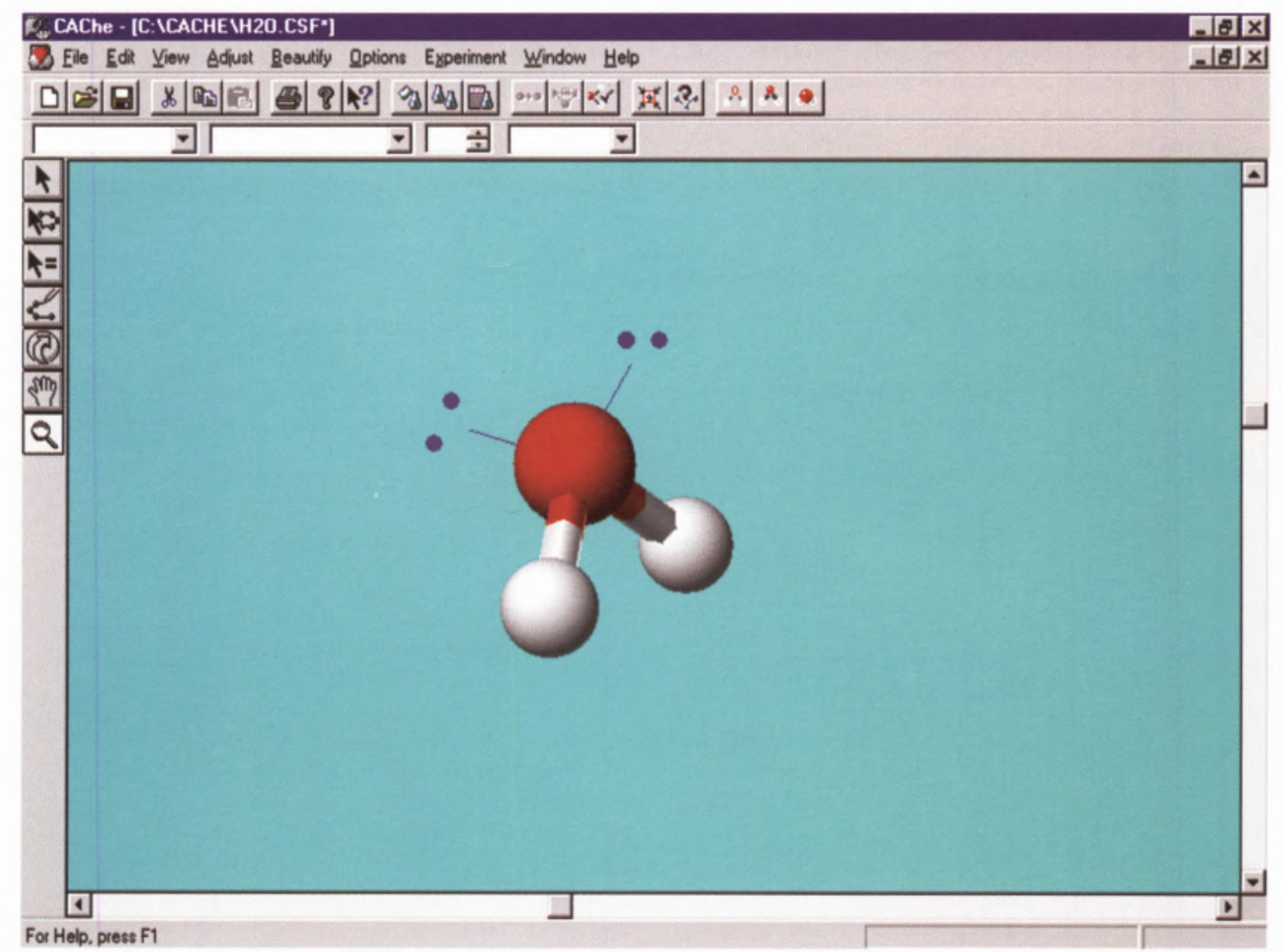

Fig. 1 - Estrutura optimizada para a água mostrando os pares de electrões não usados nas ligações 


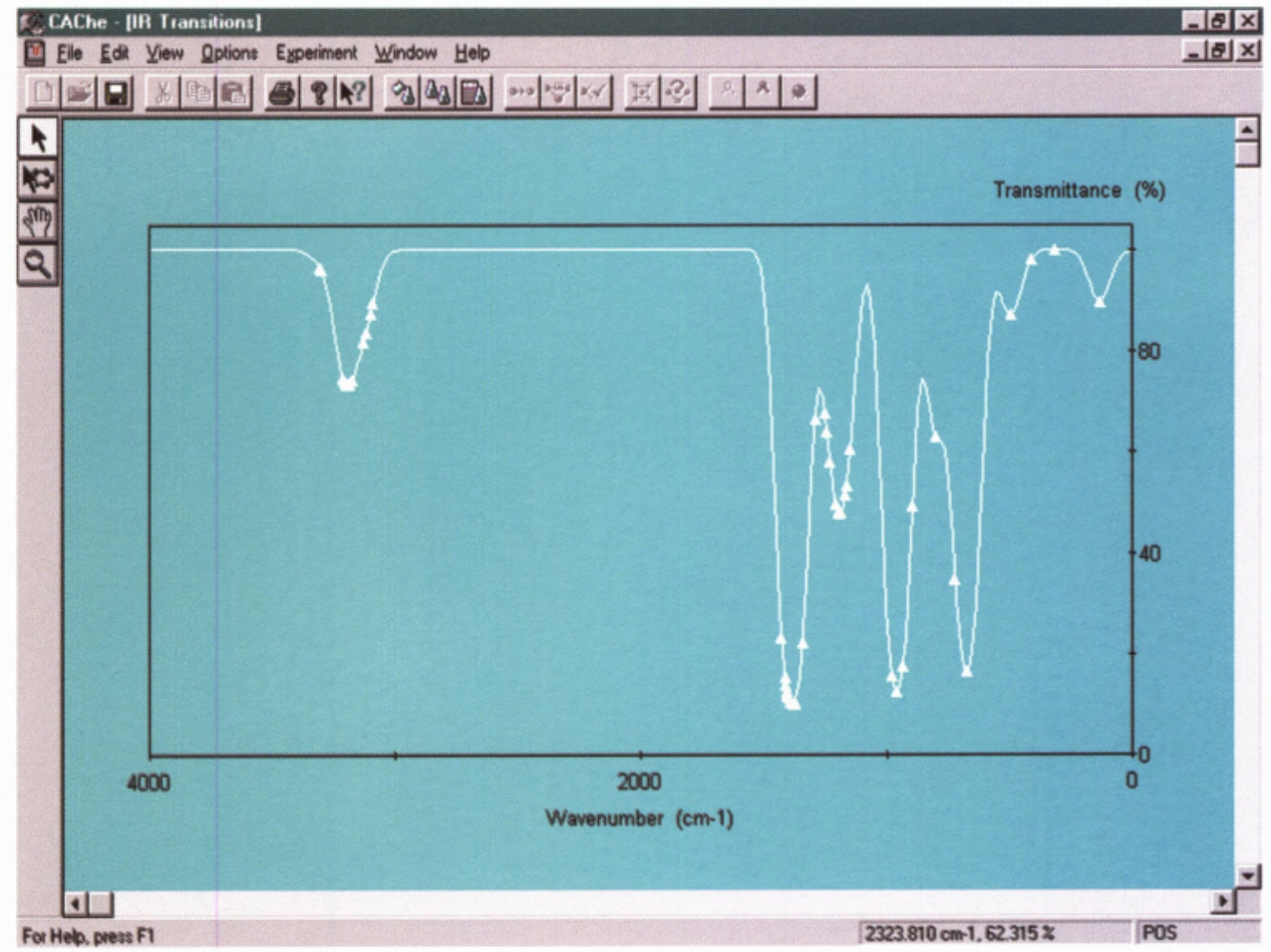

Fig. 2 - Espectro de infravermelho do hexano gasoso previsto pelo programa CAChe

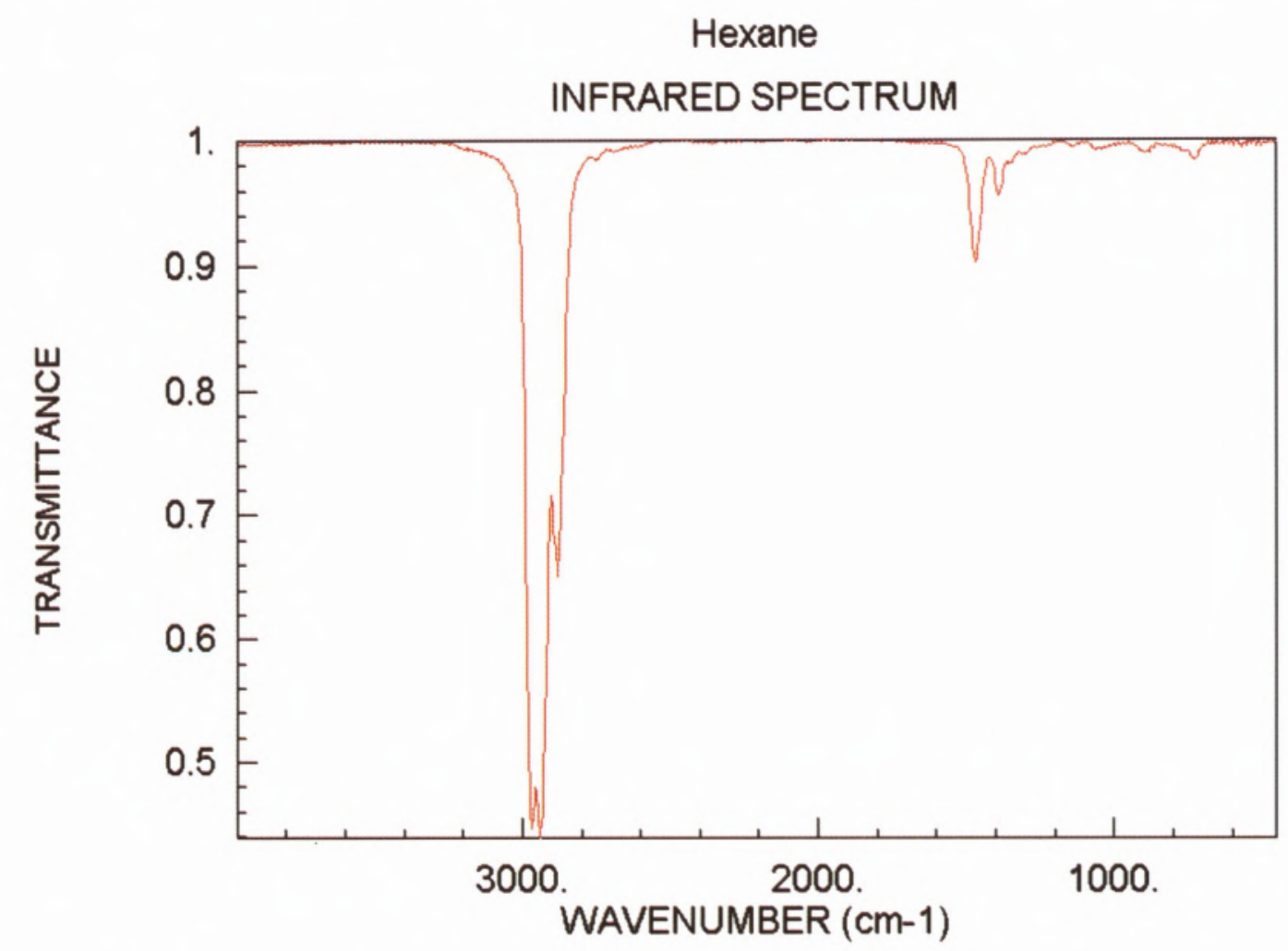

Fig. 3 - Espectro de infravermelho experimental do hexano gasoso [4] 


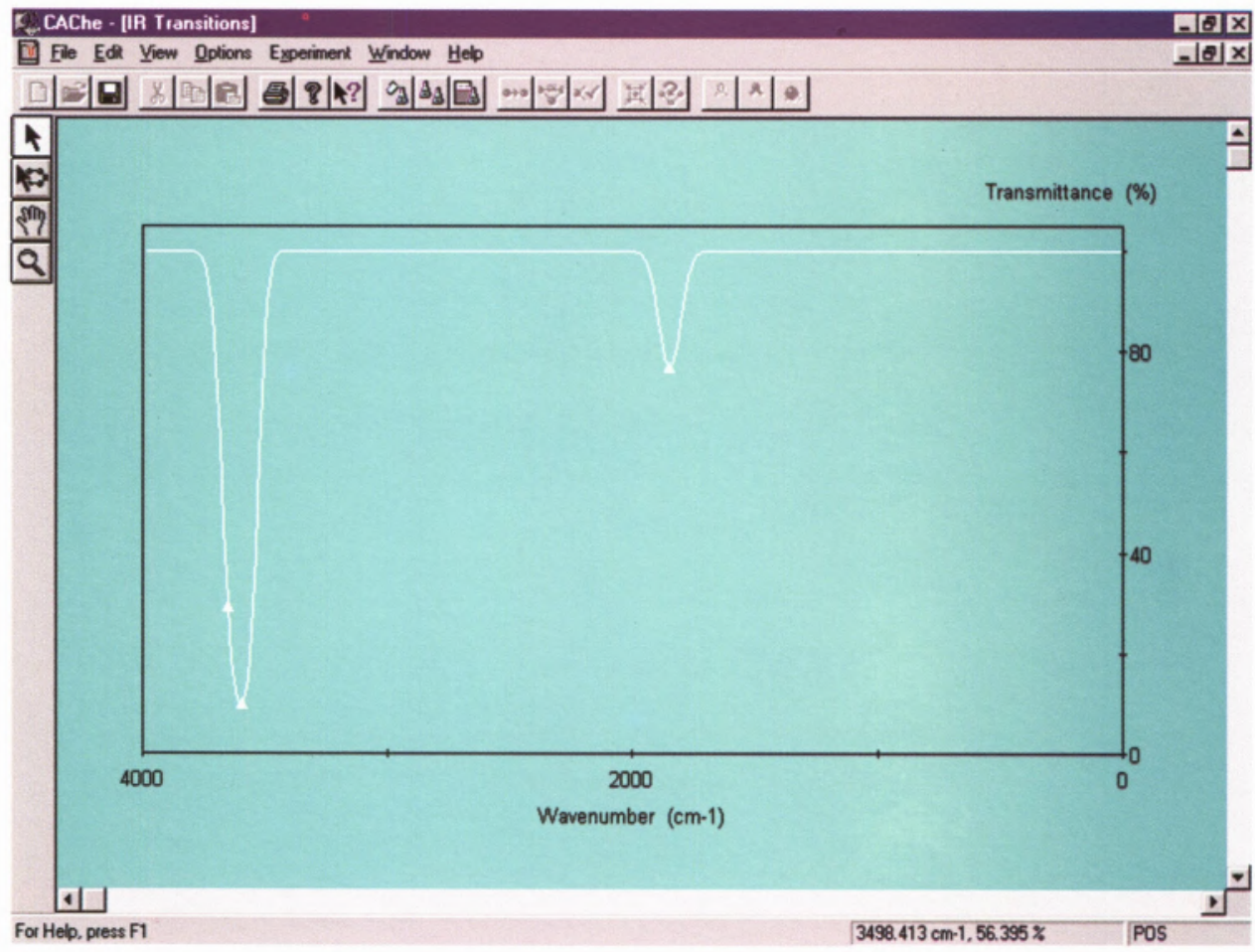

Fig. 4 - Espectro de infravermelho da água gasosa previsto pelo programa CAChe

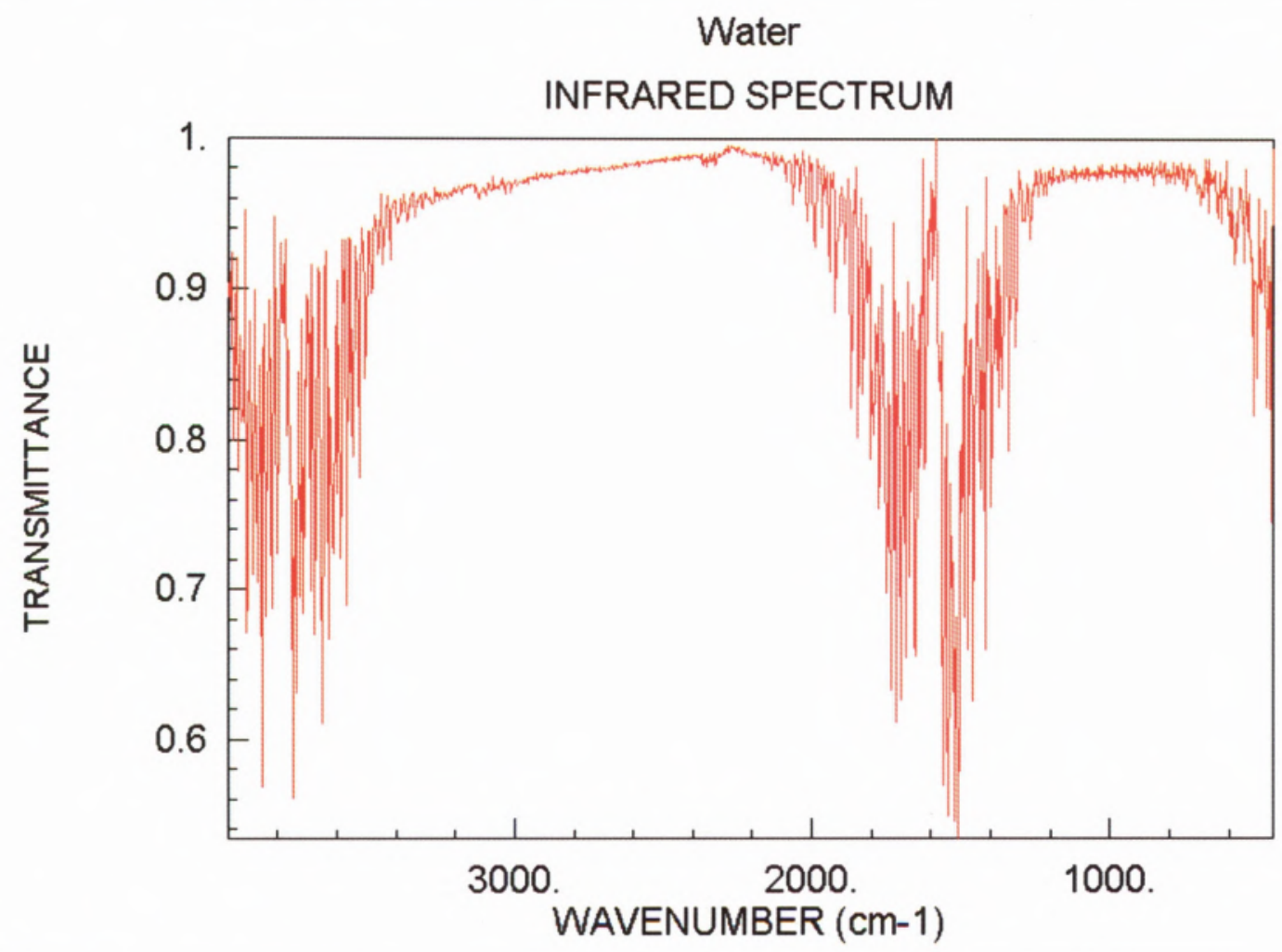

Fig. 5 - Espectro de infravermelho experimental da água gasosa [4] 
Pode ver-se que no caso da água as bandas são previstas de modo bastante aproximado mas não é prevista a estrutura das mesmas. No caso do hexano a posição das bandas está essencialmente correcta mas as intensidades relativas estão muito longe da realidade. Parece que só se deve usar os dados fornecidos pelo programa com alguma cautela e na falta de outras possibilidades.

Como mais um exemplo das potencialidades do programa apresentamse as representações gráficas da HOMO e da LUMO para o hexano (Fig. 6 e 7). Podem sobrepor-se na mesma figura duas ou mais das orbitais moleculares de uma molécula. Tal não se fez aqui para não tornar confusa a representação. Vê-se claramente que a HOMO está localizada nas ligações $\mathrm{C}-\mathrm{H}$ dos átomos centrais enquanto que a LUMO se localiza em todos os átomos de carbono do lado oposto ao dos hidrogénios.

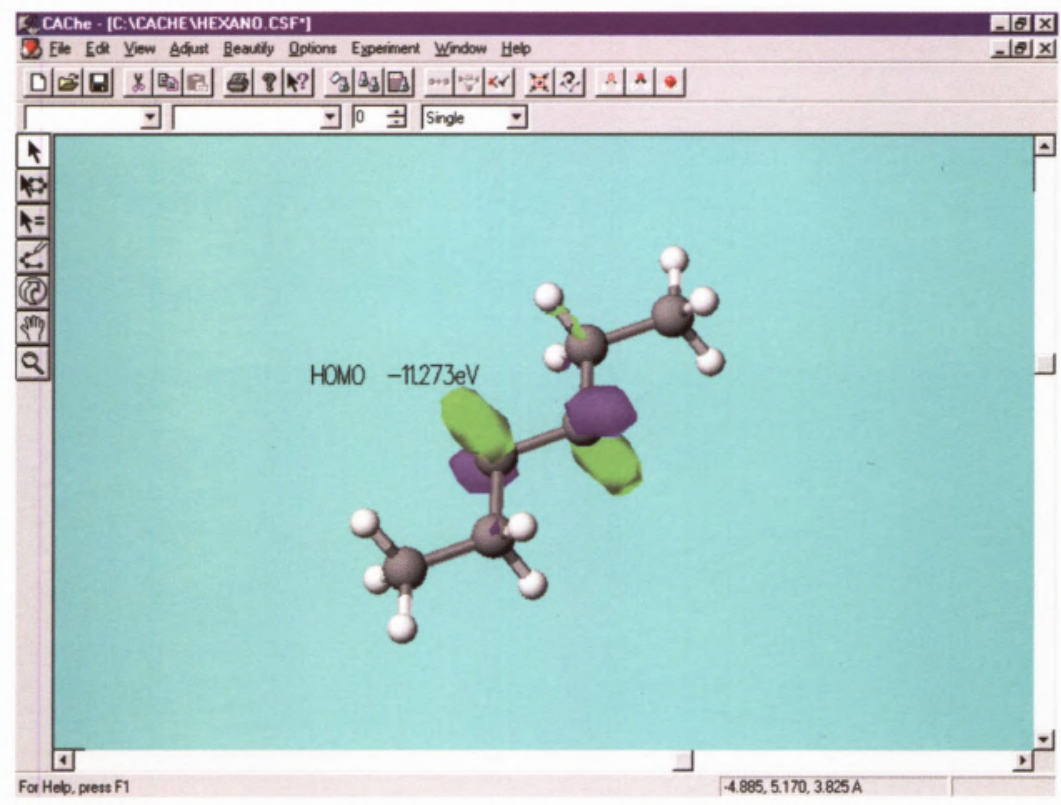

Fig. 6 - HOMO do hexano

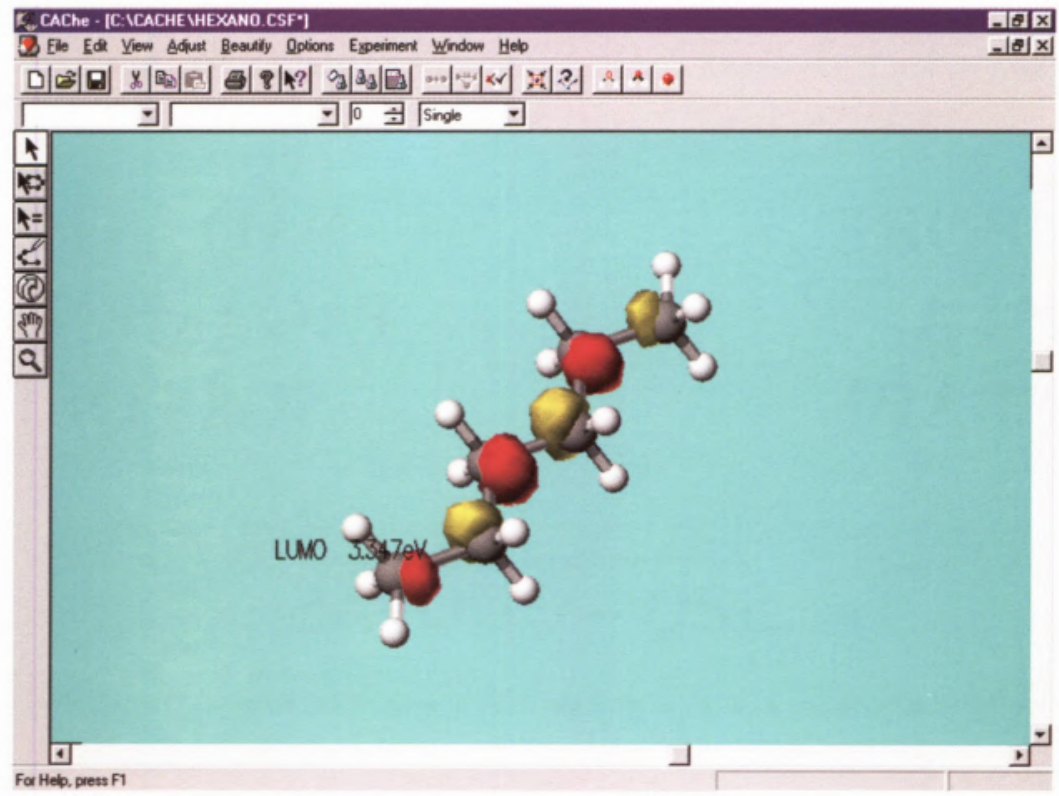


Existem muitas outras propriedades sobre as quais poderíamos debruçar-nos mas o comentário já vai longo. Não resisto, no entanto, a salientar os mapas conformacionais que nos fornecem a energia da molécula em função de parâmetros conformacionais que podem ser definidos à nossa vontade e ainda a possibilidade de refinar e verificar um estado de transição.

Finalmente uma referência ao preço. A versão analisada custou $240000 \$ 00$ em finais de 1997. Para um programa com estas potenciali- dades e tão amigável para o utilizador, embora não seja o supra-sumo nas capacidades de cálculo, parece razoável. Se puder tê-lo à mão utilize-o. Se a sua finalidade são os cálculos teóricos ao seu melhor nível existem outros programas mais adequados. Apesar de tudo o que foi dito, eu gostei do programa.

\section{REFÊRENCIAS}

1. D. D. Wagman, W. H. Evans, V. B. Parker, R. H. Schumm, I. Halow, S. M. Bailey, K. L. Churney and
R. L. Nutall, The NBS Tables of Chemical Thermodynamics Properties, J. Phys. Chem. Ref. Data, 11 (1982) Supplement $\mathrm{n}^{\circ} 2$.

2. J. B. Pedley, R. D. Naylor and S. P. Kirby, Thermochemical Data of Organic Compounds (2nd ed.), Chapman and Hall, New York, 1986.

3. J. P. Leal and J. A. Martinho Simões, J. Organomet. Chem., 460 (1993) 131.

4. NIST Mass Spec. Data Center (acedido pela WWW no endereço http://webbook.nist.gov).

* Dep. Química, ITN, Sacavém

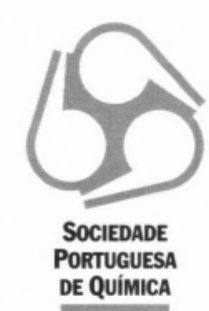

COLABORE

COM A SOCIEDADE

\section{NÃO ATRASE O PAGAMENTO DAS SUAS QUOTAS}

\section{SPQ - QUOTAS}

Sócio Efectivo

Sócio Estudante ................... $3000 \$ 00$

Sócio Casal 